\title{
Differences between Undergraduate and Graduate Students in Stress and Coping Strategies
}

\author{
Melinda J. Ickes, Joanne Brown, Brandy Reeves, and Pierre Martin D. Zephyr \\ University of Kentucky
}

\begin{abstract}
Background and Purpose: Stress among college students, and the related health and academic consequences, remains an important issue for college health professionals. Yet, less is known about the reported coping strategies among both undergraduate and graduate students. Purpose: This crosssectional study examined differences between undergraduate and graduate college students in stress levels and coping behaviors. Methods: An online health behavior survey was administered to a random sample of 1,139 college students enrolled in 2011. Chi-square test of independence examined demographic differences, stress levels and coping strategies. Classification and Regression Tree analysis further explored coping strategies which differentiated groups. Results: Participants were primarily white (87.2\%), graduate students (58.5\%), and female (59.8\%). Almost 80\% reported moderate, much or great deal of stress, with no significant differences between undergraduate and graduate students. Sleep (69.6\%), exercise (66.1\%), and food (56.8\%) were the most common coping strategies, regardless of academic classification. Social support as a coping strategy was the most important variable explaining differences between undergraduate and graduate students. Conclusion: Undergraduate and graduate college students cope with stress in a similar manner. However, social support was more likely among graduate students and may be an important strategy for future college health programming.
\end{abstract}

(c) 2015 Californian Journal of Health Promotion. All rights reserved.

Keywords: mental health, stress, college, academic, students

\section{Introduction}

Young adulthood is a period of major transition often accompanied by increased stress (Arnett, 2004). The latest American College Health Association (ACHA, 2014) report indicated that approximately half of students reported more than average or tremendous stress within the last 12 months. For those enrolled in institutions of higher education, stressors are related to independent living, developing new relationships and peer groups, issues with roommates, increased academic demands, or concerns about finances (Hicks \& Heastie, 2008). Higher levels of stress among college students have been associated with a number of adverse effects such as increased risk of illness, poor sleep, disordered eating, increased utilization of health services, and depression (Brooks, Girgenti, \& Mills, 2009; Matheny, Ashby, \& Cupp, 2005; Osberg \& Eggert, 2012; Roddenberry \& Renk, 2010; Sawatzky, Ratner,
Richardson, Washburn, Sudmant, \& Mirwaldt, 2012). Stress also has a negative impact on academic performance, as reported by more than one in three college students (ACHA, 2014). However, less is known about the difference in reported stress and related coping strategies among undergraduate and graduate students.

\section{Differences in Stress Level}

Prior research on stress among college students is well documented, although most studies have examined sex differences in perceptions of stress and reported stress level (ACHA, 2014; Brougham, Zail, Mendoza, \& Miller, 2009; Economos, Hildebrandt, \& Hyatt, 2008; Saber, Staten, Hall, \& Lennie, 2012). Such studies have found that female college students are more likely than male students to perceive higher stress levels (ACHA, 2014; Brougham et al., 2009; Economos et al., 2008). Furthermore, as female college students progress through the college years, they are more likely to experience 
increased anxiety or stress (Saber et al., 2012), while stress may actually decrease over time for males (Pettit \& DeBarr, 2011). Additional research has investigated differences in stress level among upper and lower level undergraduate students (Misra \& McKean, 2000; Pettit \& DeBarr, 2011). However, less is known about differences in stress level when comparing undergraduate and graduate students.

\section{Coping Strategies among College Students}

Coping has been defined as the "cognitive and behavioral efforts to master, reduce, or tolerate the internal and/or external demands that are created by the stressful transaction” (Lazarus \& Folkman, 1984, p.1483). Among college students, an inability to cope with stress may lead to avoidant coping, or avoidance of dealing with the stressor (Taylor, 1998), which can include risky behaviors common in college students, such as drinking, smoking, use of energy drinks, and overeating or bulimic behaviors (ACHA, 2012; Dumalo, ErdmannSager, Murray, Phan, Soukas, \& Yokuzuka, 2000; Economos et al., 2008; Labrie, Ehret, Hummer, \& Prenovost, 2012; Matheny et al., 2005; Pettit \& DeBarr, 2011). Students with higher levels of stress are more likely to practice avoidant coping (Dumalo et al., 2000), which may contribute to depression and anxiety (Staten, Hall, \& Lennie, 2012) and other adverse physical and psychological responses to stressors (Holahan \& Moos, 1987). Conversely, active coping strategies, those which are designed to change the nature of the stressor itself or how one thinks about it, are thought to be more beneficial when dealing with stress (Holahan \& Moos, 1987). Interestingly, broad distinctions of such coping strategies may have limitations for understanding stress and coping (Taylor, 1998), particularly among college students, whereas it may be necessary to operationalize avoidant and active coping strategies differently. As previously mentioned, college students are prone to participation in risky behaviors (ACHA, 2012; Dumalo, Erdmann-Sager, Murray, Phan, Soukas, \& Yokuzuka, 2000; Economos et al., 2008; Labrie, Ehret, Hummer, \& Prenovost, 2012; Matheny et al., 2005; Pettit \& DeBarr, 2011), which are often linked to avoidant coping strategies, but it should not be assumed that these behaviors are always in response to a stressor (i.e., coping strategy). Therefore, there is a need to investigate a variety of more specific coping strategies to determine differences among undergraduate and graduate college students.

\section{Stress and Coping in Graduate Students}

Although fewer studies exist among graduate students, reported stressors in this population include role conflict, time constraints, financial pressure, and lack of family or program support (Hudd, Dumlao, Erdmann-Sager, Murray, Phan, Soukas, \& Yokozuka, 2000). According to the ACHA (2014), 61\% of graduate students report more than average or tremendous stress, which is higher than the aforementioned rate of $55 \%$ among all college students. Oswalt and Riddock (2007) found that $36.8 \%$ of graduate students perceived average ability to manage stress and $31.9 \%$ did not manage their stress well, which seems in contrast to their high level of perceived health. Graduate students are also less likely to perceive that stress has an impact on their academic performance as compared to undergraduate students (ACHA, 2014). The high stress levels and inability to manage stress among graduate students is concerning, even with their perception that stress does not have an impact on health and/or academic performance. Given the paucity of research on the specific strategies graduate students utilize to cope with their high stress levels, particularly when compared to undergraduate students, further research is warranted.

\section{The Present Study}

According to the Surgeon General's Report on Mental Health, understanding the variability in response to stressful events among different individuals is a major challenge to research (U.S. Department of Health and Human Services, 1999). There is a critical need to understand selected coping strategies among college students, particularly with both undergraduate and graduate students, to guide efforts by student affairs and college health centers (Sarafino \& Ewing, 1999). The limited stress research with graduate students does not allow for adequate comparisons between these two seemingly different college populations. 
Therefore, the specific aims of this study were to: (1) determine differences in stress levels among undergraduate and graduate college students; and (2) determine differences in coping strategies among undergraduate and graduate college students. It is hypothesized that there will be a significant difference in stress level when comparing undergraduate students and graduate students. Similarly, it is hypothesized that undergraduate and graduate students will use varying coping strategies.

\section{Methods}

\section{Participants}

The university registrar of the authors' institution provided a list of 7,183 randomly selected students age 18 or older from the total study population of approximately 28,000 students that were registered for the Fall 2011 semester at a large, southeastern University. Random selection occurred within groups based upon student classification. Only students over 18 years of age were included in the study, with no exclusions based on sex or ethnicity. The overall response rate was $16.2 \%(n=1,161)$. However, due to missing data, 22 cases were deleted, resulting in a final analyzable sample of 1,139 students. Due to the de-identified nature of the data received from the registrar, it was not possible to determine the difference between non-responders and responders of the survey.

\section{Survey Measures}

The survey was an adaptation of the American College Health Association National College Health Assessment (ACHA-NCHA) (ACHA, 2013; Miller, Danner, \& Staten, 2008). The ACHA-NCHA is a widely known measure developed by an interdisciplinary group of college health experts and is considered both reliable and valid for U.S. college students (ACHA, 2013). Survey development for this study incorporated a review of relevant college health issues, panel of expert content validation, and a pilot with college students. On average, students took 15-20 minutes to complete the online survey.

The resulting survey included a total of 46 questions; a subset of the items was analyzed for this study, including all questions related to stress, coping and a number of demographic factors. Demographic items included: sex, age, race/ethnicity, student classification, first generation student status, involvement in Greek organizations, living on/off campus, and relationship status. One item assessed stress level in which participants were asked to rate their stress level in the past 30 days on a fivepoint scale from "no stress" to "a great deal of stress." Participants were then asked to select among 20 specific coping strategies they used to deal with stress in the past 12 months. They could select as many of the coping strategies as applied, which included creative pursuits, exercise, herbal remedies, hobbies, prescribed medication, pets, relaxation, sleep, social activities, spirituality, therapy, yoga, alcohol, caffeine, tobacco, drugs, food, self-injury, and sex. Coping strategies were purposely not categorized as avoidant or active due to the potential limitations of doing so among college students (Taylor, 1998).

\section{Procedures}

Approval was obtained from the University's Institutional Review Board. The randomly selected students were sent an e-mail to their official University e-mail account explaining the purpose of the study and that completion and submission of the survey implied consent for participation in the study. A hyperlink to the survey, administered through Qualtrics software (Qualtrics Labs Inc, 2013), was included in the body of the e-mail. The software program assigned each participant an individualized response ID, displayed in a table format with an IP address, but no other identifying data, to protect privacy. A reminder email was sent one week after the first email to encourage those who had not yet completed the survey. Those not responding after two weeks were considered non-responders and no further contact was made. As an incentive to participate, all students who completed the survey were given the opportunity to enter into a random drawing for a commemorative basketball signed by the coach of the University men's basketball team. At the end of the survey, respondents were directed to an embedded link which redirected them to a 
separate optional questionnaire to complete contact information for the drawing.

\section{Data Analyses}

Comparisons by stress level were grouped into three categories: 1) some stress; 2) moderate stress; and 3) much and great deal of stress. Continuous variables were summarized with descriptive statistics (n, mean, standard deviation) and categorical variables were described with counts and percentages. Summaries on demographic variables are provided overall and by academic status (i.e., undergraduate versus graduate students) (Table 1). Comparisons on stress levels between undergraduate and graduate students were performed using a chi-square test of independence. The difference in use of coping strategies for undergraduate and graduate students was investigated using a CochranArmitage test of trend. All statistical results were obtained using SAS v9.3 and Rstudio v0.96. A significance level of 0.05 was used for all statistical tests.

Classification and Regression Tree (CART) analysis is a statistical technique employed for identifying the main explanatory variables that differentiate groups, such as sex and academic status, as was used in this study. It is widely used to identify high-risk groups by classifying data into partitions based on a series of select independent variables (Breiman, Friedman, Stone, \& Olshen, 1984). Methodologically, CART analysis has two main advantages: 1) it makes no assumptions about variable distributions or relationships to other variables and 2) it is capable of identifying complex and unsuspected interactions (Breiman et al., 1984). In choosing the best variable to split, CART analysis seeks the variable with the best splitting value among all possible values to maximize the 'impurity' of the divided sample. Once the variable and the splitting value are chosen, the entire sample is divided (into nodes), which continues and branches out for each subsample until the stopping rule is applied.

Using CART analysis, we assessed the main variables that differentiated coping strategies among male undergraduate students (1) male graduate students (2), female undergraduate students (3) and female graduate students (4), as depicted in Figure 1. CART analysis was performed using the conditional inference trees (Ctree) package in the statistical analysis program R 3.0.1. The conditional inference trees were constructed with cquad-type test statistics and $\alpha=0.05$ with a simple Bonferroni correction. Each split sent at least one percent of the observations into each of the two daughter nodes. The sample size in each node was restricted to 20 observations.

\section{Table 1}

Summary of Demographic Variables among Graduate and Undergraduate Students $(\mathrm{N}=1,139)$

\begin{tabular}{|c|c|c|c|c|c|}
\hline & Total & Undergraduate & Graduate & $\chi^{2}$ & $p$ \\
\hline Gender & & & & 5.317 & 0.021 \\
\hline Male & 458 (40.2\%) & 209 (44.2\%) & 249 (37.4\%) & & \\
\hline Female & $681(59.8 \%)$ & 264 (55.8\%) & 417 (62.6\%) & & \\
\hline Age & & & & 115.320 & $<0.001$ \\
\hline $18-20$ & $19(1.7 \%)$ & 19 (4.1\%) & $0(0.0 \%)$ & & \\
\hline $21-25$ & 705 (63.5\%) & 360 (77.8\%) & 345 (53.3\%) & & \\
\hline $26-30$ & 208 (18.7\%) & 43 (9.3\%) & 165 (25.5\%) & & \\
\hline 31 or older & 178 (16.0\%) & 41 (8.9\%) & 137 (21.2\%) & & \\
\hline Race/Ethnicity & & & & 3.607 & 0.058 \\
\hline White & 992 (87.2\%) & 422 (89.4\%) & $570(85.6 \%)$ & & \\
\hline Non-white & $146(12.8 \%)$ & $50(10.6 \%)$ & $96(14.4 \%)$ & & \\
\hline $\begin{array}{l}\text { Insurance } \\
\underline{\text { status }}\end{array}$ & & & & 7.906 & 0.005 \\
\hline Uninsured & 105 (9.3\%) & 57 (12.1\%) & $48(7.2 \%)$ & & \\
\hline Insured & 1030 (90.7\%) & 413 (87.9\%) & 617 (92.8\%) & & \\
\hline $\begin{array}{l}\text { Relationship } \\
\underline{\text { status }}\end{array}$ & & & & 28.674 & $<0.001$ \\
\hline $\begin{array}{l}\text { In a } \\
\text { relationship }\end{array}$ & 386 (33.9\%) & 118 (24.9\%) & $268(40.2 \%)$ & & \\
\hline $\begin{array}{l}\text { Not in a } \\
\text { relationship }\end{array}$ & 754 (66.1\%) & 355 (75.1\%) & 399 (59.8\%) & & \\
\hline$\frac{\text { Sexual }}{\text { orientation }}$ & & & & 0.110 & 0.741 \\
\hline Heterosexual & 1050 (92.7\%) & 437 (93.0\%) & $613(92.5 \%)$ & & \\
\hline $\begin{array}{l}\text { Non- } \\
\text { heterosexual }\end{array}$ & 83 (7.3\%) & 33 (7.0\%) & 50 (7.5\%) & & \\
\hline $\begin{array}{l}\text { Fraternity } \\
\text { Sorority }\end{array}$ & & & & & 0.3079 \\
\hline Yes & 86 (18.3\%) & 86 (18.3\%) & 24 (30.0\%) & & \\
\hline No & 385 (81.7\%) & 385 (81.7\%) & $141(38.5 \%)$ & & \\
\hline $\begin{array}{l}\text { First } \\
\text { generation } \\
\text { student }\end{array}$ & & & & 0.161 & 0.688 \\
\hline$\overline{\text { Yes }}$ & $291(25.6 \%)$ & 118 (25.0\%) & 173 (26.1\%) & & \\
\hline No & 845 (74.4\%) & $354(75.0 \%)$ & $491(73.9 \%)$ & & \\
\hline
\end{tabular}




\section{Results}

\section{Demographic Variables}

The average age of the analytic sample was 26 years $(S D=6.5)$, and the sample included $41.5 \%$ $(n=473)$ undergraduate and 58.5\% $(n=666)$ graduate students. In addition, 25.6\% $(n=291)$ were first generation college students. Most of the students were females $(59.8 \%, n=681)$ and white (87.2\%, $n=992$ ) (Table 1). These demographics are somewhat different than those of the larger institution (University of Kentucky, 2013). The University has more undergraduate (71.7\%) than graduate students (25.4\%), only slightly more women than men (50.9\% versus $49.1 \%$, respectively), and majority white (78.4\%). There were significant demographic differences when comparing undergraduate and graduate students, including gender $(p=.02)$, age $(p<.001)$, insurance $(p=.005)$, and relationship status $(p<.001)$, (Table 1$)$.

\section{Table 2}

Difference between Undergraduate and Graduate Students on Coping Strategies (Chi-Square or Fischer Exact Test)

\begin{tabular}{|c|c|c|c|c|c|}
\hline & Total & $\begin{array}{l}\text { Under- } \\
\text { graduate }\end{array}$ & Graduate & $\chi^{2}$ & $p$ \\
\hline Alcohol & 474 (43.1\%) & 193 (42.9\%) & 281 (43.2\%) & 0.008 & 0.928 \\
\hline Caffeine & 85 (35.0\%) & 151 (33.6\%) & 234 (35.9\%) & 0.668 & 0.414 \\
\hline $\begin{array}{l}\text { Cigarettes/ } \\
\text { Tobacco }\end{array}$ & 163 (14.8\%) & 92 (20.4\%) & & 19.192 & $<0.001$ \\
\hline $\begin{array}{l}\text { Creative } \\
\text { pursuits }\end{array}$ & 232 (21.1\%) & 98 (21.8\%) & $134(20.6 \%)$ & 0.228 & 0.633 \\
\hline Drugs & $4(7.6 \%)$ & 45 (10.0\%) & 39 (6.0\%) & 6.069 & 0.040 \\
\hline Exerci & $\%)$ & 273 (60.7 & 455 (69.9 & 10.110 & 0.001 \\
\hline Food & & $255(56.7$ & & 0.003 & 0.956 \\
\hline $\begin{array}{l}\text { Herl } \\
\text { rem }\end{array}$ & $\%)$ & $.6 \%)$ & & 0.691 & 0.406 \\
\hline Hob & 8 (46.1\%) & 219 (48.7\%) & & 1.955 & 0.162 \\
\hline Med & 22 & 51 (11.3\%) & & 0.049 & 0.824 \\
\hline $\begin{array}{l}\text { Medi } \\
\text { Mind }\end{array}$ & 123( & $46(10.2 \%)$ & & 0.691 & 0.406 \\
\hline Pets & $94(35.8 \%)$ & 140 (31.1\%) & & 7.237 & 0.007 \\
\hline $\begin{array}{l}\text { xation/ } \\
\text { thing }\end{array}$ & & 128 (28.4\%) & 177 (27.2\%) & 0.209 & 0.647 \\
\hline Self-i & & $6(1$ & & --- & 0.171 \\
\hline Sex & 339 & 144 (32.0\%) & $.0 \%)$ & 0.523 & 0.470 \\
\hline & & 326 (72.4\%) & & 3.536 & 0.060 \\
\hline $\begin{array}{l}\text { Social } \\
\text { support }\end{array}$ & $506(46.0 \%)$ & $182(40.4 \%)$ & 324 (49.8\%) & 9.316 & 0.002 \\
\hline $\begin{array}{l}\text { Spirituality/ } \\
\text { Religion }\end{array}$ & 326 (29.6\%) & 123 (27.3\%) & 203 (31.2\%) & 1.892 & 0.169 \\
\hline $\begin{array}{l}\text { Therapy/ } \\
\text { Counseling }\end{array}$ & 74 (6.7\%) & 37 (8.2\%) & 37 (5.7\%) & 2.735 & 0.098 \\
\hline Yoga & $126(11.4 \%)$ & $51(11.3 \%)$ & 75 (11.5\%) & 0.009 & 0.924 \\
\hline
\end{tabular}

\section{Stress Level}

Students reported varying degrees of stress in the last 30 days; $21 \%$ indicated some stress, $37 \%$ indicated moderate stress, and $42 \%$ indicated much or a great deal of stress. Chi-square analyses revealed stress level differed with respect to sex $(p<0.001)$. Females reported higher levels of much stress $(48.0 \%)$ compared to males $(31.9 \%)$. There was not a significant difference $(p=.344)$ among graduate and undergraduate students, with $43.2 \%$ of graduate students and $39.5 \%$ of undergraduate students reporting much stress, $37 \%$ of both groups reporting moderate stress, and $23.4 \%$ of undergraduate and $19.5 \%$ of graduate students reporting some stress.

\section{Stress Coping Strategies}

Overall, sleep (69.3\%), exercise (66.1\%), and food $(56.8 \%)$ were the most widely reported coping strategies used to deal with stress in the past 12 months among all college students (Table 2). Significant differences did exist when comparing selected coping strategies among undergraduate and graduate students (Table 2), including: cigarettes/tobacco $(p<.001)$, drugs $(p$ $=.040)$, exercise, $(p=.001)$, pets $(p=.007)$, and social support $(p=.002)$. Undergraduate students were significantly more likely to use cigarettes/tobacco and drugs whereas graduate students were significantly more likely to use exercise, pets, and social support. Table 3 summarizes the five most commonly used coping strategies by sex and academic status. Regardless of sex or academic status, exercise, sleep, and food were common strategies for coping with stress. Graduate students and females indicated social support as another common coping strategy.

The CART analysis revealed that, among the coping strategies, the most important variable explaining differences between the students was social support (Figure 1). CART analysis split the sample between students who reported social support ( $n=505,45.5 \%)$ and those who did not report social support as a coping strategy $(n=$ $605,54.5 \%)$. Those who reported social support 


\section{Table 3}

Popular Coping Strategies by Sex and Student Status

\begin{tabular}{|c|c|c|c|}
\hline Males & Females & Undergraduate & Graduate \\
\hline $\begin{array}{l}\text { 1. Exercise } \\
(67.8 \%)\end{array}$ & $\begin{array}{l}\text { 1. Sleep } \\
(69.9 \%)\end{array}$ & $\begin{array}{l}\text { 1. Sleep } \\
(72.4 \%)\end{array}$ & $\begin{array}{l}\text { 1. Exercise } \\
(69.9 \%)\end{array}$ \\
\hline $\begin{array}{l}\text { 2. Sleep } \\
(53.0 \%)\end{array}$ & $\begin{array}{l}\text { 2. Exercise } \\
(65.8 \%)\end{array}$ & $\begin{array}{l}\text { 2. Exercise } \\
(60.7 \%)\end{array}$ & $\begin{array}{l}\text { 2. Sleep } \\
(67.1 \%)\end{array}$ \\
\hline 3. Food & 3. Food & 3. Food & 3. Food \\
\hline (44.8\%) & (57.2\%) & (56.7\%) & (56.8\%) \\
\hline 4. Alcohol & 4. Social & 4. Hobbies & 4. Social \\
\hline (43.7\%) & support & (48.7\%) & support \\
\hline 5. Hobbies & (56.5\%) & 5. Alcohol & (49.8\%) \\
\hline (43.7\%) & $\begin{array}{l}\text { 5. Alcohol } \\
(41.4 \%)\end{array}$ & (42.9\%) & $\begin{array}{l}\text { 5. Hobbies } \\
(44.4 \%)\end{array}$ \\
\hline
\end{tabular}

as a coping strategy were predominantly female undergraduate and female graduate students. Both male and female graduate students indicated social support as a coping strategy more than their respective undergraduate counterparts. Within the group that did not report social support as a coping strategy, the next level of classification was between those who reported tobacco use $(n=89,14.7 \%)$ and those who did not report tobacco use as a coping strategy ( $n=516,85.3 \%)$. About $40 \%$ of those who reported tobacco use as a coping strategy were male undergraduate students. Both female and male graduate students indicated tobacco as a coping strategy less than their respective undergraduate counterparts. Within the group that did not report tobacco use as a coping strategy, the next classification was based on whether or not they reported yoga as a coping strategy. The students who reported yoga as a coping strategy were predominantly female graduate (50\%) and female undergraduate (25\%) students. The last classification was based on whether or not they reported sex as a coping strategy, with approximately $60 \%$ identified as male graduate and male undergraduate students.

\section{Figure 1}

CART Analysis: Exploring Coping Strategies among Student Groups

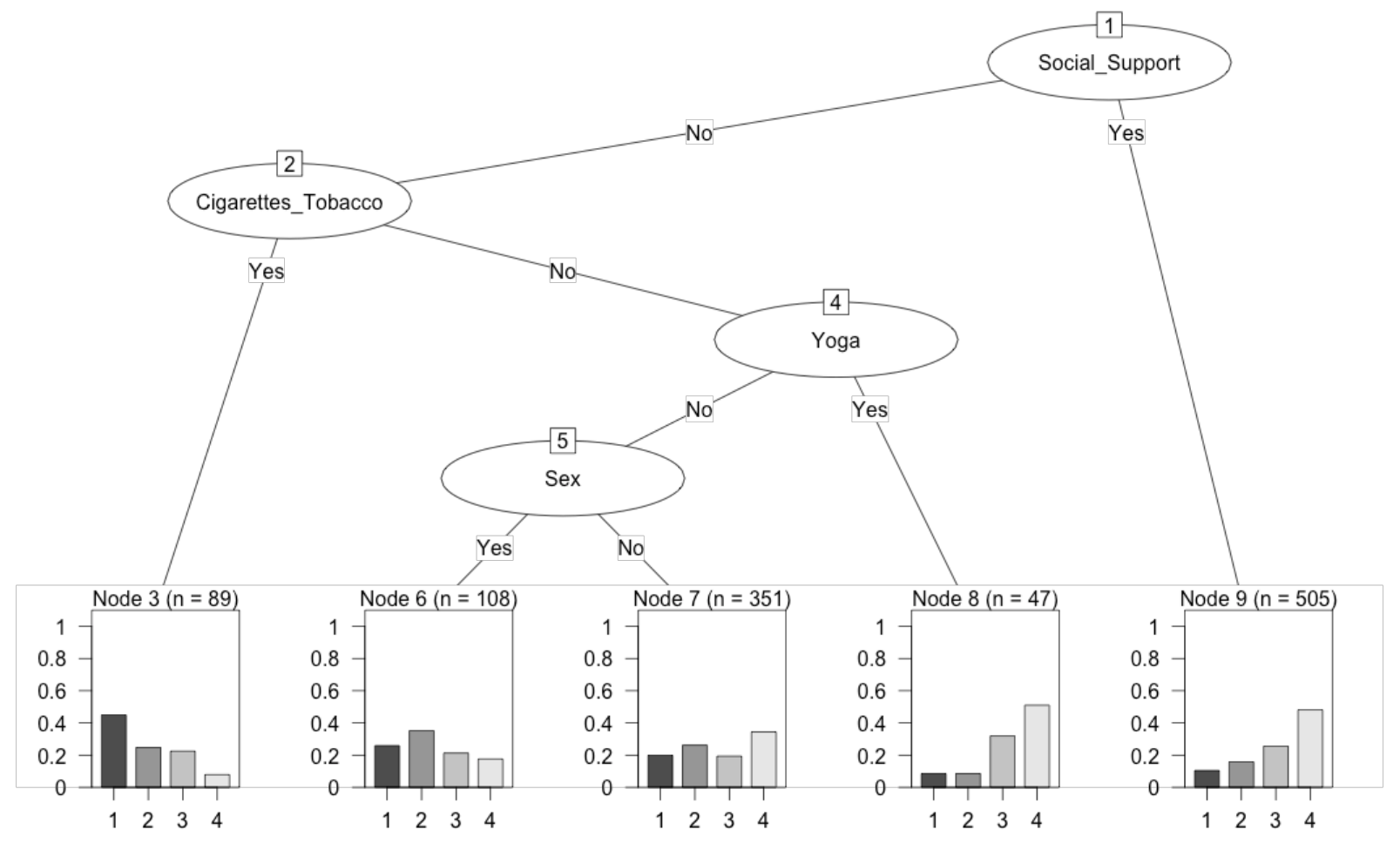

Note. Groups as represented in the nodes are as follows: male undergraduate (1), male graduate (2), female undergraduate (3), and female graduate (4) 


\section{Discussion}

\section{Stress Level}

The current study sought to explore differences in stress levels and selected coping strategies among undergraduate and graduate college students. Almost $80 \%$ of the college students in this study reported moderate, much or a great deal of stress. Common comparisons in past stress research have focused on differences between upperclassmen and underclassmen (Arnett, 2000), often leaving out the large population of graduate students enrolled at many institutions. Although there was not a significant difference between undergraduate and graduate students' stress level, with $43.2 \%$ of graduate students and $39.5 \%$ of undergraduate students reporting much stress, this in itself is an important finding considering stress has been implicated as the top factor impacting academic performance (ACHA, 2012, 2014). Future research should investigate varying sources of stress, particularly among graduate students. Little attention has been given to the stressors among graduate students as well as the shortand long-term health consequences (Hudd et al., 2000; Oswalt \& Riddock, 2007), warranting future research in these areas.

\section{Common Coping Strategies}

Considering the high levels of stress reported among both undergraduate and graduate students in this study, there is a need to understand selected coping strategies for both groups. Exercise, sleep, and food were the most common coping strategies, regardless of student status. It is encouraging that almost $70 \%$ of graduate students and $61 \%$ of undergraduate students reported using exercise as a coping strategy. Higher levels of physical activity among college students are significantly associated with lower levels of perceived stress (Nguyen-Michel, Unger, Hamilton, \& Spruijt-Metz, 2006), making participation in physical activity a recommended health promoting coping strategy. Since college students tend to voluntarily participate in physical activity to manage their stress, efforts should be made to include and promote physical activity programming throughout the academic year. Participation in physical activity classes taken for credit has been found to assist undergraduate students in controlling the stress related to other coursework (Barney, Benham, \& Haslem, 2015; Villate, 2015). However, similar research is not available with graduate students. Thus, future research is warranted to determine benefits of stress management programs which incorporate various types of physical activity with both undergraduate and graduate college students.

Sleep was the most commonly selected coping strategy among undergraduate (72\%) and the second most selected among graduate (67\%) students. Although one might be quick to categorize sleep as a health promoting coping strategy, students may be attempting to 'sleep away' stress, an avoidance tactic (Carver, Scheier, \& Weintraub, 1989). Ensuring students receive the appropriate amount of sleep on a regular basis is imperative to academic success along with overall health and wellbeing. Students with depression and anxiety and students who have interpersonal conflict report poor sleep quality (Orzech, Salafsky, \& Hamilton, 2011). Interestingly, researchers have hypothesized that poor sleep is a "gateway topic" for discussing and diagnosing mental health issues, like depression and anxiety, with college students (Orzech et al., 2011). Determining the impact of healthy sleep habits on college students' stress may be an important focus for stress management programming. In addition, it is necessary to further explore how college students use sleep as a coping strategy and their perception of this selected strategy, particularly when comparing undergraduate and graduate students.

Food was a reported coping strategy among approximately $57 \%$ of both the undergraduate and graduate students in this study. According to the most recent ACHA (2014) data, 35\% of college students were classified as overweight or obese, with slightly higher rates (37\%) among graduate students. Although this study did not investigate the selection of food as a coping strategy in relation to students' BMI, it is necessary to consider that using food to cope with stress might be a contributor to increasing rates of obesity on college campuses. Future research is needed to examine this potential link, 
particularly to explore the differences that may exist among undergraduate and graduate students. To maximize the impact of stress management programs, concepts of healthy living should be incorporated to promote overall health and target the risk of obesity among college students, regardless of academic status. Potential topics could include mindful eating, emotional eating, and healthy snacking so students who are prone to using food as a coping strategy are more confident in their ability to manage stress in a more healthful way.

\section{Differences in Coping Strategies}

Comparisons of the plethora of coping strategies college students could select from by student status revealed a few distinct differences. Undergraduate students were significantly more likely to use cigarettes/tobacco (20\%) compared to graduate students (11\%). This is not surprising given the initiation of smoking and tobacco use during the college years (Rigotti, Lee, \& Wechsler, 2000; Staten, Noland, Rayens, Hahn, Dignan, \& Ridner, 2007). However, it is concerning, and efforts to promote tobacco treatment in conjunction with stress management programs should be made. Similarly, undergraduate students were more likely to use drugs (10\%) compared to graduate students (6\%). These results are consistent with previous research on undergraduate students (Dumalo et al., 2000; Economos et al., 2008; Labrie et al., 2012; Matheny et al., 2005; Pettit \& DeBarr, 2011) in that they tend to practice avoidant coping, a term used to categorize risky health behaviors such as substance use (Dumalo et al., 2000). Tobacco use and substance abuse among college students have been linked to lower academic performance (Rigotti et al., 2000), reinforcing the importance of stress management programming which ingrains positive, health promoting coping strategies.

It would be remiss not to mention that alcohol was also ranked among the top five coping strategies by undergraduate students, although interestingly, there was not a significant difference in this selected coping strategy between undergraduate (42.9\%) and graduate students (43.2\%). This strategy can potentially result in negative health outcomes (Cohen,
Kamarck, \& Mermelstein, 1983) and appears to be a prevalent behavior in college students. This study did not assess the extent to which students reported use of alcohol to cope with stress (i.e., drinking in moderation compared to binge drinking). However, it is important to consider that, nationally, $23 \%$ of college students reported binge drinking once or twice in the past two weeks and $11 \%$ reported three or more times in the past two weeks (ACHA, 2014). Rates of binge drinking among undergraduates tend to be slightly higher; $24 \%$ once or twice and $12 \%$ three or more times in the past two weeks compared to $20 \%$ once or twice and $5 \%$ three or more times in the past two weeks reported by graduate students. Future research should investigate contributing factors of those reporting alcohol as a coping strategy, particularly in comparison to their alcohol consumption. Given the potential consequences of this coping strategy (National Center for Chronic Disease Prevention and Health Promotion, 2012), future stress management programs on college campuses should integrate alcohol prevention strategies and promote alternate coping strategies.

Graduate students were significantly more likely to report exercise, pets, and social support as coping strategies as compared to undergraduate students. These are often categorized as active coping strategies and are thought to be more beneficial when dealing with stress (Holahan \& Moos, 1987). Although graduate students in this study had similar levels of stress in comparison to undergraduate students, they may be more adept at coping, thereby reducing the impact on academic performance and/or related health outcomes. Future longitudinal studies are necessary to truly understand the effects of these varying coping strategies on college students and ultimately to understand why more undergraduate students are not selecting similar coping strategies.

\section{The Role of Social Support}

An innovative approach to understanding descriptive data, the CART analysis revealed that the most important variable explaining differences between student groups was social support. Social support can include support from 
peers, family, faculty, and even the college campus (Allgower, Wardle, \& Steptoe, 2001). Overall, graduate students $(50 \%)$ were more likely to report social support as a coping strategy compared to undergraduate students (40\%). However, female graduate students were much more likely to report social support as a coping strategy as compared to all other groups. This is consistent with previous research in that females are significantly more likely to use social support compared to males (Tamres, Janicki, \& Helgeson, 2002). Nonetheless, these findings are of interest because of the resulting differences in social support as a coping strategy between undergraduate and graduate students. Social support has been found to positively impact stress levels and well-being, including overall life satisfaction and happiness (Chao, 2012; Cohen et al., 1983; Lundberg, McIntire, \& Creasman, 2008). Students who report low levels of social support are more susceptible to the effects of stress, (Chao, 2012), more likely to report life dissatisfaction and even suicidal behavior (Allgower et al., 2001), and tend to engage in unhealthy behaviors, including use of alcohol, lack of physical activity, and low levels of sleep (Thorsteinsson \& Brown, 2008).

This was apparent in the CART analysis as well: of the students who did not select social support as a coping strategy in this study, $15 \%$ reported tobacco use. Undergraduate students, particularly male undergraduates, were more likely to select tobacco as a coping strategy. When experiencing stress, it is critical that students know that support is available (Chao, 2012), or students may turn to other risky health behaviors, such as tobacco use, as an alternative. Future stress management programming should integrate strategies to enhance and cultivate social support, particularly among undergraduate students. In addition, the value of social support as a health promoting coping strategy should be highlighted. Additional research is needed to determine the nature of social support experienced and needed by both undergraduate and graduate college students, particularly as it relates to stress outcomes.

\section{Limitations}

The cross-sectional design, use of one college setting, and low response rate were limitations in this study. Future longitudinal studies would strengthen an understanding of how college students use various coping strategies, dependent on stress level. Also, the included college population was fairly homogenous, with $87 \%$ of the participants being white; thus, caution should be used when extending these results to other college campuses with more diverse racial or ethnic groups. The average age of the participants was 26 years, with an increased response rate among graduate students. Considering traditional aged college students tend to be 18-22 years, results may not be generalized to all college students. However, the analyses differentiated stress level and coping strategies by academic status to account for such a split sample.

In addition, the survey items asked about selfreported stress level and coping strategies, but did not investigate reasons for reported stress. This is an area needing more investigation, particularly among graduate students. Similarly, the survey was focused on specific health issues of interest to University clinicians and did not provide the opportunity to further link all related behaviors and coping strategies. These areas would be important to investigate in future studies, particularly in terms of the short- and long-term health outcomes. The authors also chose to examine reported coping strategies in the past 12 months and reported stress in the past 30 days, so coping strategies may not be indicative of current strategies employed to handle stress. Finally, this survey was administered in September, a few weeks into a new semester. Time series analysis would be informative to determine patterns of stress level and coping strategies among college students throughout the academic year.

\section{Implications}

This study reinforces there is a need for stress management programming on college campuses, programming which targets both undergraduate and graduate students. Further, understanding specific strategies used by college students to cope with higher perceived stress levels may 
provide college administrators, counselors, health educators, and healthcare providers useful information to assist with program development to enhance student success. The reality is, stress is a multi-dimensional issue, and must be treated as such when interpreting perceived stress levels and selected coping strategies among undergraduate and graduate students. Undoubtedly more research is needed, both in understanding stress from the undergraduate and graduate student perspective, and in evaluating outcomes of efforts to encourage health promoting coping strategies in stress management programs.

\section{Conclusion}

Considering the increasing demands placed on college students, it is no surprise that almost $80 \%$ of the study participants reported moderate, much, or a great deal of stress. Little attention has been paid to the differences in coping strategies among undergraduate and graduate students. Interestingly, similar trends emerged across these groups, with exercise, sleep, and food the most commonly reported coping strategies, regardless of student status. However, distinct differences also existed, with undergraduate students more likely to use tobacco and drugs, both risky health behaviors, as a coping strategy compared to graduate students. The most important variable explaining differences between student groups was social support, with graduate students considerably more likely to report this coping strategy. Considering the benefits of social support (Chao, 2012; Cohen et al., 1983; Lundberg et al., 2008), this coping strategy should be promoted with all students. There is a need to further understand the rationale for selected coping strategies among diverse groups of college students. Knowing how different groups of students experience and cope with stress can ensure college health programming is explicitly targeted and more successful (Maibach \& Parrott, 1995).

\section{References}

Allgower, A., Wardle, J., \& Steptoe, A. (2001). Depressive symptoms, social support, and personal health behaviors in young men and women. Health Psychology, 20, 223-227.

Arnett, J. (2004). Emerging adulthood: The winding road from the late teens through the twenties. New York, NY: Oxford University Press.

American College Health Association. (2013). American College Health Association-National College Health Assessment: Generalizability, reliability, and validity analysis. Available at: www.acha.org/grvanalysis.html. Accessed April 1, 2013.

American College Health Association. (2014). American College Health Association-National College Health Assessment II: Reference group executive summary Spring 2014. Available at: www.acha.org. Accessed March 6, 2014.

American College Health Association. (2012). Healthy Campus 2020. Available at: http://www.acha.org/HealthyCampus/student-obj.cfm. Accessed April 1, 2013.

Barney, D., Benham, L., \& Haslem, L. (2014). Effects of college students' participation in physical activity classes on stress. American Journal of Health Studies, 29(1), 1-6.

Breiman, L., Friedman, J., Stone, C. J., \& Olshen, R. A. (1984). Classification and regression trees. Washington, DC: Chapman \& Hall/CRC.

Brooks, P. L., Girgenti, A., \& Mills, M. (2009). Sleep patterns and symptoms of depression in college students. College Student Journal, 43(2), 464-472.

Brougham, R. R., Zail, C. M., Mendoza, C. M., \& Miller, J. R. (2009). Stress, sex differences, and coping strategies among college students. Current Pscyhology, 28, 85-97.

Carver, C. S., Scheier, M. F., \& Weintraub, J. K. (1989). Assessing coping strategies: A theoretically based approach. Journal of Personality and Social Psychology, 56, 267-283.

Chao, R. C. (2012). Managing perceived stress among college students: The roles of social support and dysfunctional coping. Journal of College Counseling, 15(1), 5-21.

Cohen, S., Kamarck, T., \& Mermelstein, R. (1983). A global measure of perceived stress. Journal of Health and Social Behavior, 24, 385-396. 
Dumlao, J., Erdmann-Sager, D., Murray, D., Phan, E., Soukas, N., \& Yokozuka, N. (2000). Stress at college: Effects on health habits, health status and self-esteem. College Student Journal, 34(2), 11.

Economos, C., Hildebrandt, L., \& Hyatt, R. (2008). College freshman stress and weight change: Differences by gender. American Journal of Health Behaviors, 32(1), 16-25.

Hicks, T., \& Heastie, S. . (2008). High school to college transition: A profile of the stressors, physical and psychological health issues that affect the first-year on-campus college student. Journal of Cultural Diversity, 15(3), 143-147.

Holahan, C. J., \& Moos, R. H. (1987). Personal and contextual determinants of coping strategies. Journal of Personal Social Psychology, 52(5), 946-955.

Hudd, S. S., Dumlao, J., Erdmann-Sager, D., Murray, D., Phan, E., Soukas, N., \& Yokozuka, N. (2000). Stress at college: Effects on health habits, health status and self-esteem. College Student Journal, 34(2), 217.

Labrie, J., Ehret, P., Hummer, J., \& Prenovost, K. (2012). Poor adjustment of college life mediates the relationship between drinking motives and alcohol consequences: A look at college adjustment, drinking motives, and drinking outcomes. Addictive Behaviors, 37, 379-386.

Lazarus, R., \& Folkman, S. (1984). Stress, Appraisal, and Coping. New York: Springer Publishing Company.

Lundberg, C. A., McIntire, D. D., \& Creasman, C. T. (2008). Sources of social support and self-efficacy for adult students. Journal of College Counseling, 11, 58-72.

Maibach, E., \& Parrott, R. L. (1995). Designing health messages: Approaches from communication theory and public health practice. California: SAGE Publications.

Matheny, K. B., Ashby, J. S., \& Cupp, P. (2005). Gender differences in stress, coping, and illness among college students. The Journal of Individual Psychology, 61(4), 365-379.

Miller, K., Danner, F., \& Staten, R. (2008). Relationship of work hours with selected health behaviors and academic pregress among a college student cohort. Journal of American College Health, 56(6), 675-679.

Misra, M., \& McKean, M. (2000). College students' academic stress and its relation to their anxiety, time management and leisure satisfaction. American Journal of Health Studies, 16(1), 41-51.

National Center for Chronic Disease Prevention and Health Promotion. (2012). CDC Vital Signs: Binge drinking nationwide problems local solutions. Available at: http://www.cdc.gov/Vitalsigns/BingeDrinking/. Accessed April 1, 2013.

Nguyen-Michel, S. T., Unger, J.B., Hamilton, J., \& Spruijt-Metz, D. (2006). Associations between physical activity and perceived stress/hassles in college students. Stress and Health, 22(3), 179188.

Orzech, K. M., Salafsky, D.B., \& Hamilton, L.A. (2011). The state of sleep among college students at a large public university. Journal of American College Health, 59(7), 612-619.

Osberg, T. M., \& Eggert, M. (2012). Direct and indirect effects of stress on bulimic symptoms and BMI: The mediating role of irrational food beliefs. Eating Behaviors, 13(1), 54-57.

Oswalt, S. B., \& Riddock, C. C. (2007). What to do about being overwhelmed: Graduate students, stress and university services. College Student Affairs Journal, 27(1), 24-44.

Pettit, M. L., \& DeBarr, K. A. (2011). Perceived stress, energy drink consumption, and academic performance among college students. Journal of American College Health, 59(5), 335-341.

Qualtrics Inc. (2013). Qualtrics Software. Vol.37,892. Provo, UT: Qualtrics Research Suite.

Rigotti, N., Lee, J. L., \& Wechsler, H. (2000). US college students use of tobacco products: Results of a national survey. Journal of the American Medical Association, 284(6), 699-705.

Roddenberry, A., \& Renk, K. (2010). Locus of control and self-efficacy: potential mediators of stress, illness, and utilization of health services in college students. Child Psychiatry Human Developement, 41(4), 353-370. 
Saber Raja Mahmoud, J., Staten, R. T., Hall, L. A., Lennie, T. A. (2012). The relationship among young adult college students' depression, anxiety, stress, demographics, life satisfaction, and coping styles. Issues in Mental Health Nursing, 33, 149-156.

Sarafino, E. P., \& Ewing, M. . (1999). The hassles assessment scale for students in college: Measuring the frequency and unpleasantness. Journal of American College Health, 48(2), 75-87.

Sawatzky, R. G., Ratner, P. A., Richardson, C. G., Washburn, C., Sudmant, W., \& Mirwaldt, P. (2012). Stress and depression in students: The mediating role of stress management self-efficacy. Nursing Research, 61(1), 13-21.

Staten, R. T., Hall, L. A., \& Lennie, T. A. (2012). The relationship among young adult college students' depression, anxiety, stress, demographics, life satisfaction, and coping styles. Issues in Mental Health Nursing, 33(3), 149-156.

Staten, R. R., Noland, M., Rayens, M.K., Hahn, E., Dignan, M., \& Ridner, L. S., (2007). Social influences on cigarette initiation among college students. American Journal of Health Behavior, 31(4), 353362.

Tamres, L. K., Janicki, D., \& Helgeson, V. S. (2002). Sex differences in coping behavior: A meta-analytic review and an examination of relative coping. Personality and Social Psychology Review, 6(1), 35-64.

Taylor, S. (1998). Coping strategies. MacArthur Research Network on SES \& Health. Available from: http://www.macses.ucsf.edu/research/psychosocial/coping.php

Thorsteinsson, E. B., \& Brown, R. F. (2008). Mediators and moderators of the stressor-fatigue relationship in nonclinical samples. Journal of Psychosomatic Research, 66, 21-29.

U.S. Department of Health and Human Services. (1999). Mental health: A report of the Surgeon General. Rockville, MD. Available from: profiles.nlm.nih.gov/ps/access/NNBBHS.pdf

University of Kentucky. (2013). Univeristy of Kentucky fact booklet. Available at www.uky.edu/IRPE/fast_facts/fact_booklet/fact_booklet1112.pdf. Accessed March 5, 2015.

Villate, V. M. (2015). Yoga for college students: An empowering form of movement and connection.. The Physical Educator, 72, 44-66.

Wohlgemuth, E., \& Betz, N. (1991). Gender as a moderator of the relationships of stress and social support to physical health in college students. Journal of Counseling Psychology, 38(3), 367-374.

\author{
Author Information \\ *Melinda J. Ickes, Ph.D. \\ Assistant Professor \\ Department of Kinesiology and Health Promotion \\ College of Education \\ University of Kentucky \\ 111 Seaton Building \\ Lexington, KY 40506-0219 \\ 859-257-1625 \\ Melinda.ickes@uky.edu \\ Joanne Brown, DNP, APRN \\ Advanced Practice Provider \\ University Health Service \\ University of Kentucky \\ Lexington, KY \\ Brandy Reeves, MPH, MSEd, CHES \\ Director of Student Affairs \\ College of Public Health
}




\section{University of Kentucky \\ Lexington, KY}

Pierre Martin D. Zephyr

Statistician

Applied Statistics Lab

University of Kentucky

Lexington, KY

* corresponding author 